\title{
The impact of alcohol pharmacotherapies on public health in Australia is limited by low prescribing rates
}

\author{
Paul S Habera,b,c and Kirsten C Morley ${ }^{b}$
}

a Drug Health Services, Royal Prince Alfred Hospital, Sydney, NSW, Australia

${ }^{b} \mathrm{NHMRC}$ Centre of Research Excellence in Mental Health and Substance Use, University of Sydney, NSW, Australia

c Corresponding author: paul.haber@sydney.edu.au

\section{Article history}

Publication date: September 2016

Citation: Haber PS, Morley KC. The impact of alcohol pharmacotherapies on public health in Australia is limited by low prescribing rates. Public Health Res Pract. 2016;26(4):e2641643. doi: http://dx.doi. org/10.17061/phrp2641643

\section{Key points}

- Acamprosate and naltrexone are effective treatments for alcohol dependence, with effect sizes similar to those of antidepressants in the treatment of depression. Both medicines have been listed on the Pharmaceutical Benefits Scheme since 2001

- Diagnosis and treatment rates of alcohol dependence are unsatisfactory in Australia

- Rates of prescribing are low (almost 3\% for those with alcohol dependence) and have changed little over the past decade. Consequently, the public health impact of these treatments is likely to be minimal

- This problem could only be addressed by a major change in public policy to remove multiple barriers to uptake of effective management for alcohol use disorders

\section{Abstract}

Alcohol use disorders are among the most common and disabling problems in Australia. A number of pharmacotherapies available in Australia have been shown to be effective and are subsidised through the Australian Government's Pharmaceutical Benefits Scheme. The uptake of these medicines is poor, and the majority of those who start treatment do not complete the recommended course. Use of these medicines is significantly lower in regions that are disadvantaged or remote, and in patients who are younger. Taken together, these factors limit the potential benefit to population health from treatment of alcohol use disorders. Barriers to treatment have been identified at the level of the patient, the provider, the medicine and the healthcare system. An integrated strategy may be required to overcome these barriers.

\section{Introduction}

Australia-wide, alcohol use accounts for an annual economic burden exceeding $\$ 30$ billion, including harms to drinkers and to others ${ }^{1}$, and is a major cause of drug-related death, second only to tobacco. ${ }^{2}$ Among regular users of alcohol, the average daily use of more than two standard drinks is associated with increased risk of harms. Accordingly, national guidelines for low-risk consumption of alcohol recommend less than two standard drinks per day on average. ${ }^{3}$ It has been argued that the burden of harm from drinkers who exceed guidelines is greater than that of the smaller number of people with an alcohol use disorder (AUD), who drink at the highest levels. ${ }^{4}$ Nonetheless, people with an AUD form a large group at greater individual risk of harm, both to themselves and to others (including their children), and AUD is a significant public health issue in Australia. Almost 2 million Australians will be affected if the most recent and inclusive definition in the Diagnostic and Statistical Manual of Mental Disorders (DSM-5) is adopted ${ }^{5}$, or about a third of this number if a more stringent definition is used. ${ }^{5}$ AUDs affect young people, with a modal age of onset of 18 years. The traditional male predominance remains, but AUDs are increasingly common in women. 


\section{Treatment options for alcohol dependence}

A number of treatments have been shown to be effective for AUDs, including psychosocial and pharmacological interventions. The efficacy of these interventions matches or exceeds those in general use for disorders such as depression. Acamprosate and naltrexone are the most commonly used 'anti-craving' pharmacotherapies internationally for the treatment of alcohol dependence and are subsidised through the Pharmaceutical Benefits Scheme (PBS) in Australia. Naltrexone is an orally active nonspecific opioid antagonist with a moderate but statistically reliable effect in reducing heavy drinking, as demonstrated in meta-analyses of randomised controlled trials. ${ }^{6}$ Acamprosate is a synthetic GABA analogue that is thought to restore N-methyl-D-aspartate (NMDA) receptor tone following increased neuronal hyperexcitability during alcohol withdrawal. Acamprosate has been shown to be effective in the majority of controlled trials and by meta-analysis. ${ }^{6}$ There is limited evidence in support of other pharmacotherapies such as disulfiram, baclofen and topiramate. These agents are not listed on the PBS and are infrequently used. The bulk of the published research describes the use of medicines in populations where alcohol dependence was defined by DSM-IV, with few studies demonstrating efficacy for alcohol abuse as defined by DSM-IV or for AUD as defined by DSM-5.

Psychosocial treatment options have been shown to be effective, including motivational interviewing and cognitive behavioural therapy ${ }^{7}$, with evidence accumulating in support of newer psychotherapies such as mindfulness. ${ }^{8}$ Other treatment modalities include long-term residential rehabilitation programs and 12-step programs such as Alcoholics Anonymous, although the evidence of efficacy is mixed. ${ }^{9}$ The Self Management and Recovery Training (SMART) approach adapts evidence based strategies such as cognitive behavioural therapy principles for use in a mutual support group framework, and is gaining acceptance in Australia. ${ }^{10}$ Nonetheless, the most widely available and used intervention for alcohol dependence is still Alcoholics Anonymous.

Although AUDs are leading causes of preventable disability and death, few of those affected will seek any form of treatment. Treatment is typically started late (an average of 18 years after the onset of the disorder) and after accumulation of complications. ${ }^{11}$ Only $2.6 \%$ of those with an AUD receive any treatment within the first year of symptomatic disorder. ${ }^{11}$ Lifetime treatment rates in Australia were estimated at 78\% for DSM-IV alcohol dependence and only $28 \%$ for DSM-IV alcohol abuse. ${ }^{11}$ These numbers are based on a definition of treatment as "had ever talked to a healthcare professional (including complementary healthcare workers) about their use of alcohol". Therefore, this definition of treatment would include a number of non-evidence based strategies, as well as commencement of potentially effective treatment without completion. The uptake and completion of evidence based treatment is therefore lower than these figures indicate, although it is difficult to estimate by how much. One area for optimism is that people born after 1978 were more likely to receive treatment than those born before 1958. Those with a failure to fulfil social roles were twice as likely to receive treatment compared with those not reporting these problems. ${ }^{11}$

\section{Alcohol pharmacotherapy prescription data}

Acamprosate and naltrexone have been listed on the PBS since 2001 for people with alcohol dependence, establishing a continuing clinical role for the medicines. National treatment guidelines recommend naltrexone or acamprosate as first-line therapy with a minimum 90-day treatment period. ${ }^{7}$ Consequently, these medicines have the potential to yield a substantial public health benefit. These medicines cost substantially more than the copayment for PBS medicines, so there is a major financial incentive for patients to obtain medicine through the PBS rather than through private prescriptions that would not be included in PBS data. Accordingly, PBS data include almost all use of these medicines and can be used to monitor treatment uptake. Disulfiram is not listed on the PBS and is apparently infrequently used, although there are no data in the public domain.

The crude number of total prescriptions captured on the PBS dispensed per year in New South Wales (NSW) increased by roughly 50\% between 2004 and $2014 .{ }^{12}$ The crude rate of dispensed alcohol pharmacotherapy was approximately 23 per 1000 individuals in 2011-2012 ${ }^{12}$, up from 13 per 1000 in 2001 . Nonetheless, less than $3 \%$ of individuals with alcohol dependence in Australia are being dispensed these medicines ${ }^{12}$, although the prevalence rate for alcohol dependence is 3.9\%. ${ }^{5}$ For naltrexone, just $42 \%$ of initial dispenses were followed by a second dispense, and only $25 \%$ received at least 3 months of treatment. For acamprosate, $28 \%$ of dispenses were followed by a second dispense, with only $15 \%$ receiving at least 3 months of treatment.

Patients in older age groups were about three times more likely to dispense a repeat script than those in younger age groups. ${ }^{12}$ These data indicate that, even when pharmacotherapy is taken up, few patients complete the recommended 3-month course of treatment, and fewer still are in the younger age groups. It has also been observed that socio-economic disadvantage and geographical remoteness strongly influence dispensing of these medicines, whereby significantly less pharmacotherapy is prescribed per capita in remote regions and in disadvantaged areas. ${ }^{13}$ This disparity is particularly concerning in the light of evidence that AUD is associated with a social gradient, such that the disorders are more common in disadvantaged groups and in regional areas of Australia. ${ }^{13}$ These data suggest 
that existing pharmacotherapy is not being targeted to those communities with the greatest need.

In Australia, there is a focus on short-term use of medicines to assist withdrawal for alcohol dependence, most commonly using benzodiazepines. The place of benzodiazepines in relapse prevention is very limited, with no recognised evidence of efficacy, but they are occasionally prescribed in the hope of preventing relapse to heavy drinking. There are no contemporary data describing how commonly this occurs.

\section{Barriers to treatment}

Overall, use of these medicines is limited and prescribing rates are low, which tends to undermine the potential for public health benefit from treatment. Multiple barriers at every level of the therapeutic process may contribute to low use, including patient-based, physician-based, medicine-based and system-based barriers (Table 1). It is likely that an integrated set of solutions need to be implemented to increase medicine use and subsequently improve the treatment of AUDs. Patient-level barriers - such as stigmatisation of AUD and strong beliefs about the nature of the disorder and treatment - may be difficult to overcome without national intervention. Provider interventions appear more feasible and include education and training opportunities. There have been periodic clinical reviews in major journals ${ }^{14}$, national clinical guidelines ${ }^{7}$, and professional training activities at both undergraduate and postgraduate levels. Clinical training opportunities could dispel misconceptions and change provider attitudes. Development of more effective pharmacotherapies that are well tolerated would be a major advance that would inevitably increase uptake of treatment. Strategies to overcome treatment barriers at the system level could focus on AUD as an area for service development. These could include establishing treatment targets for AUD in NSW public sector services, expanding consultation liaison services within hospitals, starting pharmacotherapy in hospital (where relevant), and integrating treatment of AUD with related healthcare such as mental health, general medical services and aged care services.

\section{Increasing uptake of pharmacotherapy}

There is a growing body of literature regarding the role of general practitioners (GPs) in the detection and prescribing of pharmacotherapy for AUD. ${ }^{15}$ However, while screening and brief interventions for AUD are integrated into general practice, treatment is uncommonly initiated unless the case is severe. ${ }^{16}$ Treatment before the onset of disability is clearly desirable, and this would include strategies to improve the role of GPs in early treatment. The evolution of a specialist addiction medicine workforce has the potential to legitimise treatment of
Table 1. Selected barriers to increasing uptake of pharmacotherapy for AUD

\begin{tabular}{|c|c|}
\hline Barrier & Examples \\
\hline Patient based & $\begin{array}{l}\text { - } \quad \text { Poor recognition of AUD } \\
\text { - } \quad \text { Not willing to enter treatment } \\
\text { - } \text { Not interested in pharmacotherapy } \\
\text { - Poor access to care } \\
\text { - Stigmatisation of AUD }\end{array}$ \\
\hline Provider based & $\begin{array}{ll}\text { - } & \text { Lack of knowledge } \\
\text { - } & \text { Reluctant to treat AUD } \\
\text { - } & \text { Lack of confidence } \\
\text { - } & \text { Reluctant to prescribe } \\
& \text { pharmacotherapy }\end{array}$ \\
\hline Medicine based & $\begin{array}{l}\text { - } \text { Adverse effects } \\
\text { - Delayed or limited efficacy } \\
\text { - Inconvenient dosing schedule } \\
\text { - Cost }\end{array}$ \\
\hline System based & $\begin{array}{l}\text { - } \quad \text { Lack of advocacy } \\
\text { - } \quad \text { Lack of treatment services } \\
\text { - } \quad \text { Lack of system performance monitoring } \\
\text { or target setting } \\
\text { - Poor reimbursement for treatment } \\
\text { of AUD }\end{array}$ \\
\hline
\end{tabular}

AUD = alcohol use disorder

disorders such as AUD. There is the potential to establish shared care programs to support treatment by GPs with specialist support. The Australian Government's Medicare reimbursement for specialists in addiction medicine will be improved from 1 November 2016, and this provides an opportunity to expand treatment for AUD and other substance use disorders.

The uptake of pharmacotherapy for AUD is poor, but improving treatment options, treatment systems, provider development and patient engagement could increase uptake and, in turn, improve clinical outcomes from this common and disabling disorder.

\section{Acknowledgements}

This work is supported by funding from the National Health and Medical Research Council and NSW Health.

\section{Competing interests}

$\mathrm{PH}$ has been a paid member of the International Advisory Committee for pharmaceutical company Lundbeck.

\section{Author contributions}

$\mathrm{PH}$ and $\mathrm{KM}$ developed the outline for the paper, drafted and revised the paper. 


\section{References}

1. Laslett A-M, Catalano P, Chikritzhs T, Dale C, Doran C, Ferris $\mathrm{J}$, et al. The range and magnitude of alcohol's harm to others. Canberra: Alcohol Education and Rehabilitation Foundation; 2010 [cited 2016 Aug 29]. Available from: www.fare.org.au/wp-content/uploads/research/TheRange-and-Magnitude-of-Alcohols-Harm-to-Others.pdf

2. Chikritzhs TN, Jonas HA, Stockwell TR, Heale PF, Dietze PM. Mortality and life years lost due to alcohol: a comparison of acute and chronic causes. Med J Aust. 2001;174(6):281-4.

3. National Health and Medical Research Council. Australian guidelines to reduce health risks from drinking alcohol. Canberra: Commonwealth of Australia; 2009 [cited 2016 Aug 29]. Available from: www.nhmrc.gov. au/_files_nhmrc/publications/attachments/ds10-alcohol. pdf

4. Kreitman N. Alcohol consumption and the preventive paradox. Br J Addict. 1986;81(3)353-63.

5. Mewton L, Slade T, McBride O, Grove R, Teesson M. An evaluation of the proposed DSM- 5 alcohol use disorder criteria using Australian national data. Addiction. 2011;106(5):941-50.

6. Jonas DE, Amick HR, Feltner C, Bobashev G, Thomas K, Wines R, et al. Pharmacotherapy for adults with alcohol use disorders in outpatient settings: a systematic review and meta-analysis. JAMA. 2014;311(18):1889-900.

7. Haber P, Lintzeris N, Proude E, Lopatko O. Guidelines for the treatment of alcohol problems: prepared for the Australian Government Department of Health and Ageing. Canberra: Commonwealth of Australia; 2009 [cited 2016 Aug 29]. Available from: www.health.gov.au/ internet/main/publishing.nsf/Content/OFD6C7C289CD31 C9CA257BF0001F96BD/\$File/AustAlctreatguidelines\%20 2009.pdf
8. Witkiewitz K, Bowen S. Depression, craving, and substance use following a randomized trial of mindfulness-based relapse prevention. J Consult Clin Psychol. 2010;78(3):362-74.

9. Ferri M, Amato L, Davoli M. Alcoholics Anonymous and other 12-step programmes for alcohol dependence. Cochrane Database Syst Rev. 2006(3):CD005032.

10. Kelly PJ, Deane FP, Baker AL. Group cohesion and between session homework activities predict selfreported cognitive-behavioral skill use amongst participants of SMART Recovery groups. J Subst Abuse Treatment. 2015;51:53-8.

11. Chapman C, Slade T, Hunt C, Teesson M. Delay to first treatment contact for alcohol use disorder. Drug Alcohol Depend. 2015;147:116-21.

12. Morley KC, Logge W, Pearson SA, Baillie A, Haber PS. National trends in alcohol pharmacotherapy: findings from an Australian claims database. Drug Alcohol Depend. 2016;166:254-7.

13. Morley KC. Socioeconomic and geographic disparities in access to pharmacotherapy for alcohol dependence in Australia. Aust N Z J of Public Health. (Under review, copy on file with author).

14. Connor JP, Haber PS, Hall WD. Alcohol use disorders. Lancet. 2016;387(10022):988-98.

15. Berends L, Lubman D. Obstacles to alcohol and drug care: are Medicare Locals the answer? Aust Fam Physician. 42(5):339-42.

16. Rehm J, Anderson P, Manthey J, Shield KD, Struzzo P, Wojnar M, Gual A. Alcohol use disorders in primary health care: what do we know and where do we go? Alcohol Alcohol. 2016;51(4):422-7.

\section{Copyright: (c) (i) (2)}

(C) 2016 Haber and Morley. This article is licensed under the Creative Commons Attribution-NonCommercial-ShareAlike 4.0 International Licence, which allows others to redistribute, adapt and share this work non-commercially provided they attribute the work and any adapted version of it is distributed under the same Creative Commons licence terms. See: www.creativecommons.org/licenses/by-nc-sa/4.0/ 